\title{
EVALUATION OF SEISMIC BEHAVIOR OF IRREGULAR TUBE BUILDINGS IN TUBE SYSTEMS
}

\author{
Hojat Allah Ghasemi ${ }^{1}$ \\ 1 Department of Civil Engineering, Imam Hussein University, Tehran, Iran, e-mail: ghasemisah@gmail.com
}

Received: 2015.12.15

Accepted: 2016.02.01

Published: 2016.03.01

\begin{abstract}
Setbacks in the volume of a building usually arise from the demands of urban design for illumination, proportion, etc. However, in seismic events they are the cause of abrupt changes in stiffness and mass producing a concentration of stresses in the floors near the site of sudden change. In general terms, one should ensure that the transitions are as gradual as possible in order to avoid such concentration of stresses. This study is intended to investigate seismic behavior of irregular building tube in tube systems, for this purpose seismic behavior of 40-story and 60-story reinforced concrete frame building with irregular plan was evaluated, seismic behavior of irregular buildings was assessed by overall building drifts, story drifts and shear lag behavior factors.. Higher irregularities in the overall plan structure of a building increase the phenomena of story drift and shear lag phenomena. Story drift and shear lag are higher for 60 -story building than for a 40-story building.
\end{abstract}

Keywords: seismic behavior, irregular building, tube in tube systems.

\section{INTRODUCTION}

Buildings are complex and multiple systems . Hence, at the planning stage itself, architects and structural engineers must work together to ensure that unfavourable features are avoided and good building configuration is chosen. If we have a poor configuration to start with, all that engineers can do is to provide a band-aid i.e. improve a basically poor solution as best as they can [1].

Conversely, if we start with a good configuration and reasonable framing system, even a poor engineer cannot harm its ultimate performance too much. Structural irregularities are one of the most frequent causes of severe damages in buildings, as evidenced by the numerous earthquakes in recent years. This issue is of particular importance, since almost all real structures are irregular. Furthermore, structural irregularities depend on several factors, often very difficult to predict.

This study are to investigate the effects of performance of tube in tube structure with irregular plan. In past, large research efforts were devoted to the study of the seismic response of irregular structures in plan [2, 3]. Over the past ten years, the framed tube has been accepted as an economical system for controlling the drift of tall buildings under seismic loading. The framed tube can be thought of as a hollow tube with rectangular cutouts for windows. Horizontal loads are resisted by tensile and compressive forces in the sides of the tube which are perpendicular to the loads, and by bending and shearing forces in the sides which are parallel to the loads. In this sense the framed tube can be compared to a beam in which the sides of the tube perpendicular to the loads are the flanges of the beam and the sides parallel to the load are the web. During the tube action, unfavourable shear lag inevitably occurs. The shear lag phenomenon is characterized by non-uniform axial forces or stresses applied in the columns or walls of the peripheral flanges and/or by nonlinear stress distributions in the peripheral webs (Figure 1).

Framed-tube structures with multiple internal tubes, or tubes-in-tube structures, can be assessed as a system capable of maximizing the structural efficiencies. The shear lag phenomenon is more prominent in framed tube structures with multiple 
a)
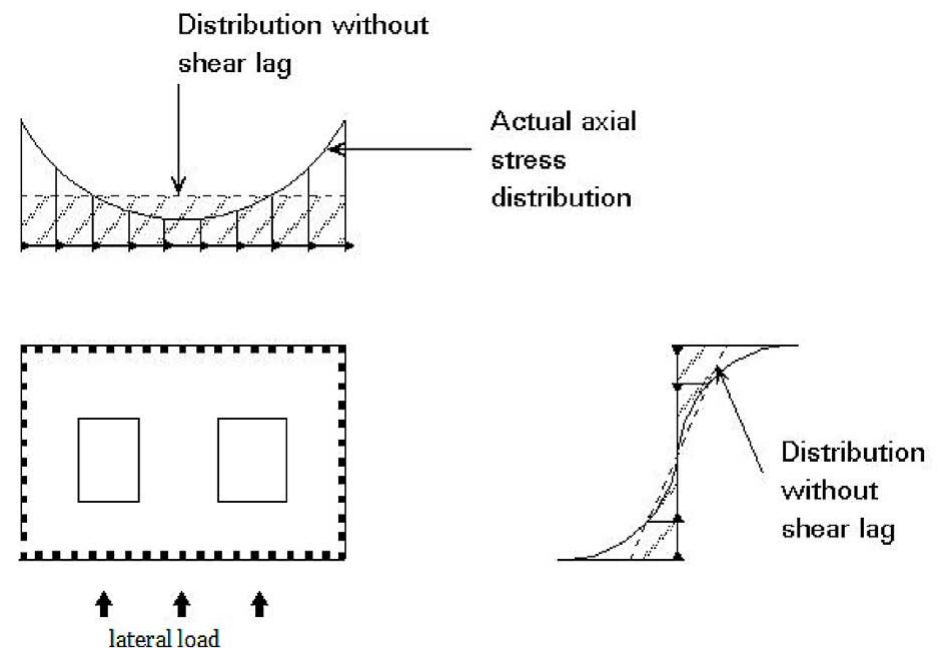

b)

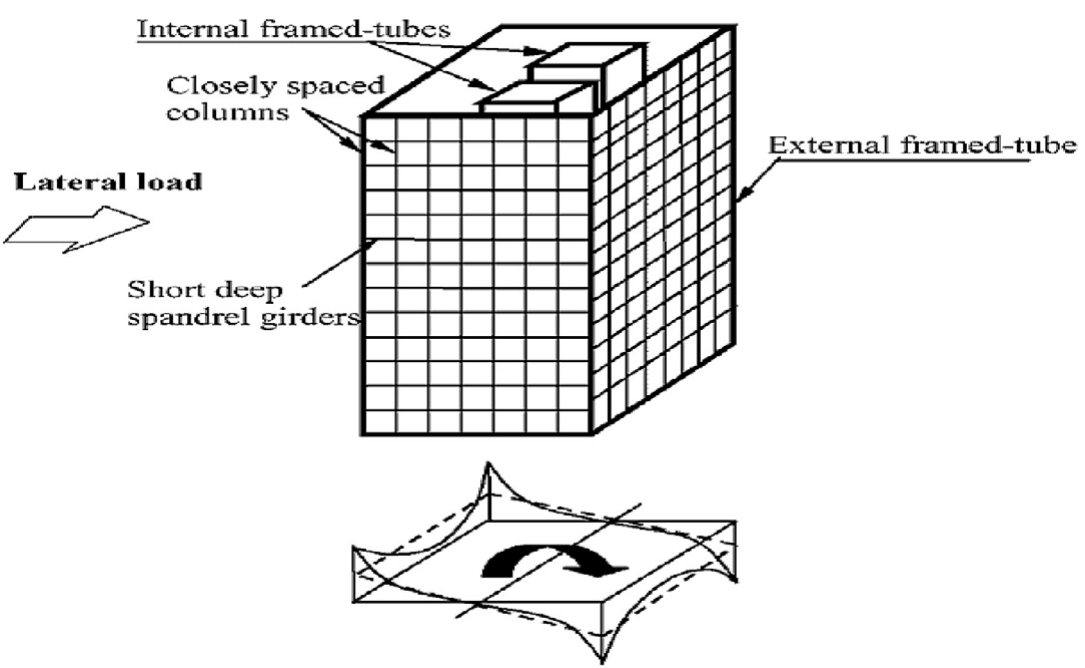

Fig. 1. Stress distribution in the external frame of the bottom story of a framed-tube structure

internal tubes. The use of multiple internal tubes reduces the effect of shear lag in the tubes, induces more effective participation of internal columns in resisting lateral forces and offers additional lateral stiffness to the structure. Kristek and Bauer [4], Singh and Nagpal [5] and Lee et al. [6] extended the study to examine the shear lag behaviour of single and multiple framed-tube buildings.

\section{STRUCTURAL SYSTEM OF THE CASE STUDY BUILDING}

Figure 2 illustrates a 3-D model of 40-storey and 60-story reinforced concrete frame tube in a tube system. The 40-story structure is $148 \mathrm{~m}$ tall and 60 -story structure is $220 \mathrm{~m}$. Both buildings are $32.4 \times 32.4 \mathrm{~m}$ (wide $\times$ length). The story height is $4 \mathrm{~m}$ at the first story and $3.6 \mathrm{~m}$ at the upper story. Columns dimension in the 40-story building is $1 \times 1$ and in the 60 -story building $-1.30 \times 1.30$ $\mathrm{m}$, columns span are constant and equal $3.5 \mathrm{~m}$ in all direction. Slab thickness in both buildings are $300 \mathrm{~mm}$ and shear wall thickness in the 40-story and 60 -story building is $500 \mathrm{~mm}$ and $800 \mathrm{~mm}$ for all typical floors. The concrete compressive strength $400 \mathrm{~kg} / \mathrm{cm}^{2}$ were used for all members. Both buildings have tow tubs that are located in the exterior frame, distance of tube $3.6 \mathrm{~m}$ considered in both buildings.

\section{RESPONSE SPECTRUM METHOD MODELING AND ASSUMPTION ANALYSIS}

The modern seismic codes, such as Eurocode 8 [7], allow using different analysis methodologies: 1) lateral force, 2) modal response spectrum, 3) static nonlinear and 4) dynamic nonlinear analyses. Their level of reliability decreases from 4) to 1) and, consequently, the safety margin with respect to the same limit state should increase according to the same order [8]. Linear dynam- 

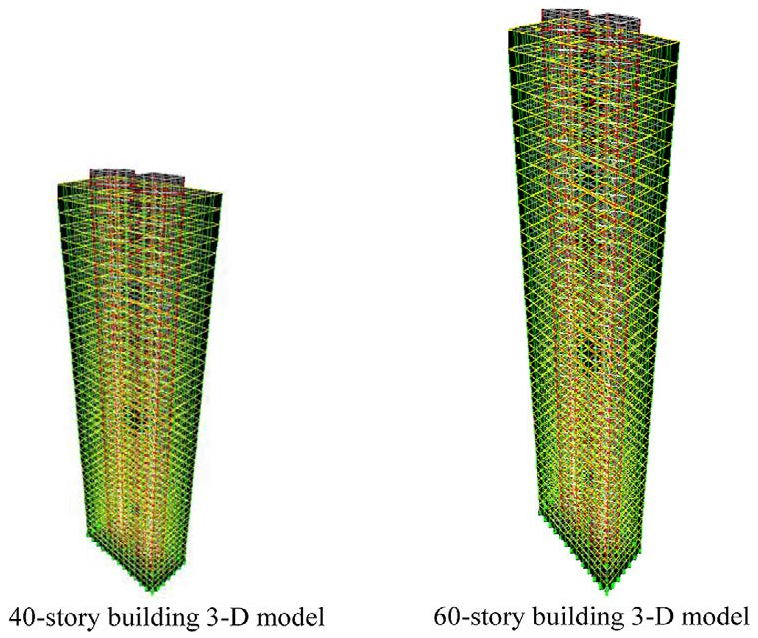

Fig. 2. ETABS 3-D models of the case study buildings

ic analysis of the building models is performed using ETABS. The lateral loads generated by ETABS correspond to the high risk seismic zone and 5\% damped response spectrum given in IS 1893-2002 (Part 1) [9]. The fundamental natural period values are calculated by ETABS, by solving the eigenvalue problem of the model. Thus, the total earthquake load generated and its distribution along the height corresponds to the mass and stiffness distribution as modelled by ETABS. ETABS building analysis and design software (v9.7.4; Computers and Structures Inc. ((CSI), 2011) has been used for the modelling and analysis of this study. Analysis approaches used for this study are summarized in the following:

1) Joints between the beams and columns (parts of both beams and columns belonging to their common regions) are assumed rigid. It should be noted that varying the column (or beam) depth of the frames changes the beam (or column) length between the column faces, so as to also affect the beam (or column) stiffness due to this assumption.

2) The contribution of the slab to the beam stiffness (i.e., T-beam action) is ignored.

3) The concrete floors are modelled with rigid diaphragm constraints for lateral force analysis.

4) P-delta effects are taken into account by an approximate method imbedded in ETABS (CSI, 20011) [10].

5) The flexural stiffness of uncracked shear walls is assumed to correspond to $100 \%$ of the gross section properties, while the flexural stiffness of all spandrel beams and coupling beams is taken as 50\% based on ACI 318-08, Section 8.8 (ACI 318,2008$)$ [11]. It has been verified from the models that the shear walls are expected not to undertake cracking at all stories under the lateral forces used for this study. Detailed discussions for the finite element modelling of cracked shear walls can be found elsewhere.

\section{METHODOLOGY}

Many buildings in the present scenario have irregular configurations in plan. In the future, they may be the subject to devastating earthquakes. In case, it is necessary to identify the performance of the structures to withstand seismic load. Figure 3 shows a plan of the case study buildings, for evaluating the seismic response of irregular building, performance of regular building compared with irregular plan.

\section{STORY DRIFT}

One of the first requirements of performance evaluation is the selection of one or more performance objectives, i.e.: select desired performance level and associated seismic hazard level. Since the evaluation relies on analysis rather than experimentation, the criteria should be stated in terms of a response that can be calculated. Depending on the intensity of the ground motion, a different performance objective will be desired. In general, different performance levels will require different design criteria to be applied to different design parameters. At one end of the performance spectrum, content damage is often proportional to floor accelerations, which can be limited by reducing stiffness. At the other end of the spectrum, life safety and collapse prevention are controlled by inelastic deformation capacity of ductile members and strength capacity of brittle members. As a result, no single design parameter may satisfy all performance requirements. No single damage measure will provide all the information required to assess structural performance, especially at all performance objectives. However, some indicator must be used to provide quantitative limits. Peak transient drift serves as an indicator of damage to low strength rigid elements, such as building cladding and partition walls, and the maximum deformation of the structural elements. The use of maximum values as an indicator of damage provides preliminary information to be used in the evaluation of the structural system. Figure 


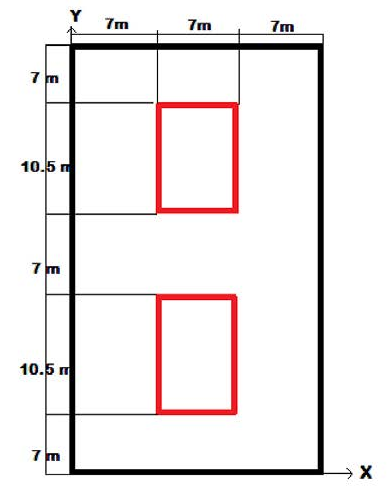

Model (a)

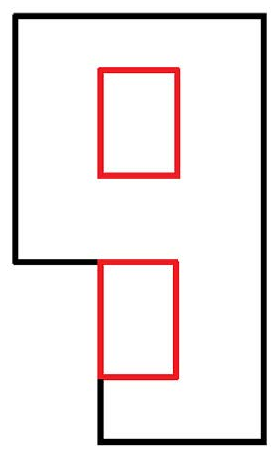

model (b)

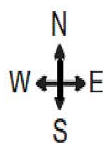

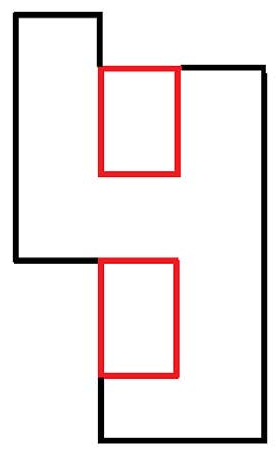

model (c)

Fig. 3. Plans of case study for 40-story and 60-story buildings

a)

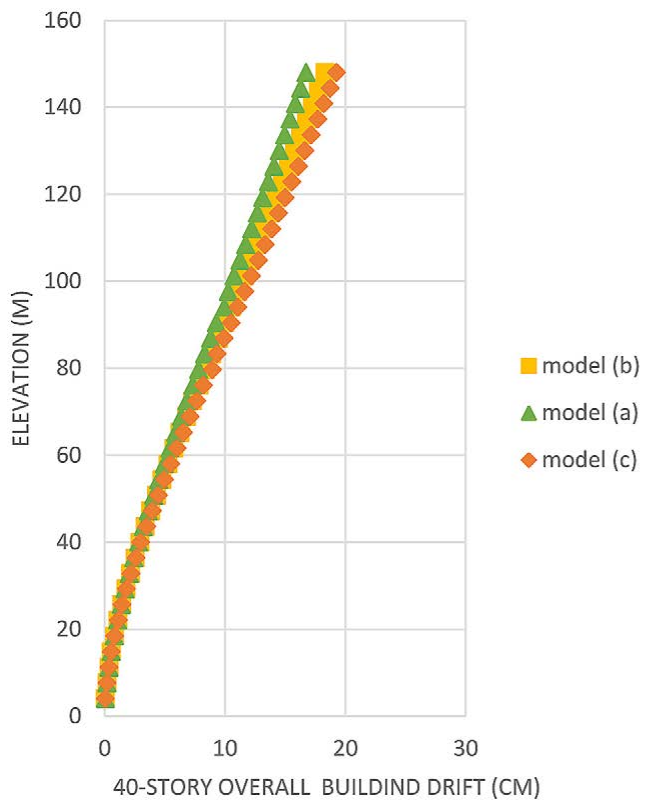

b)

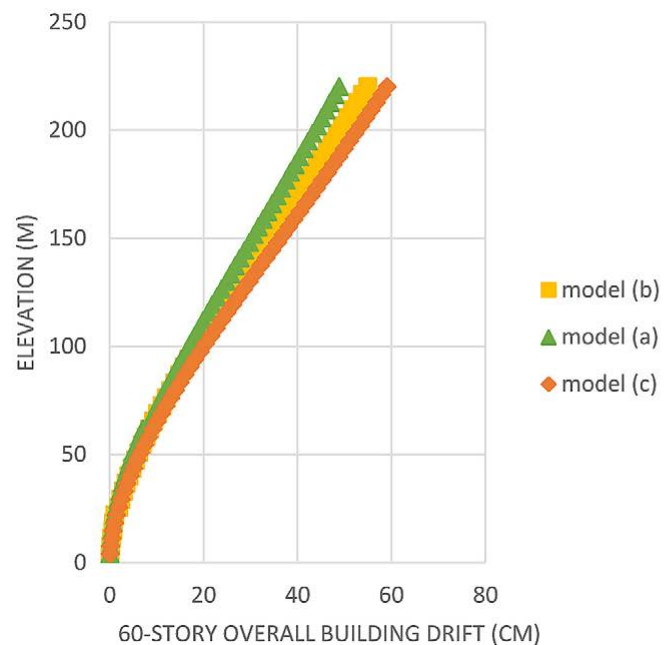

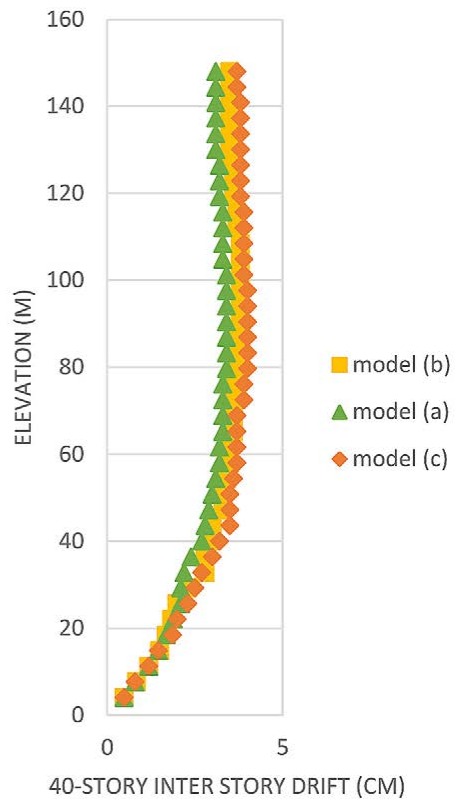

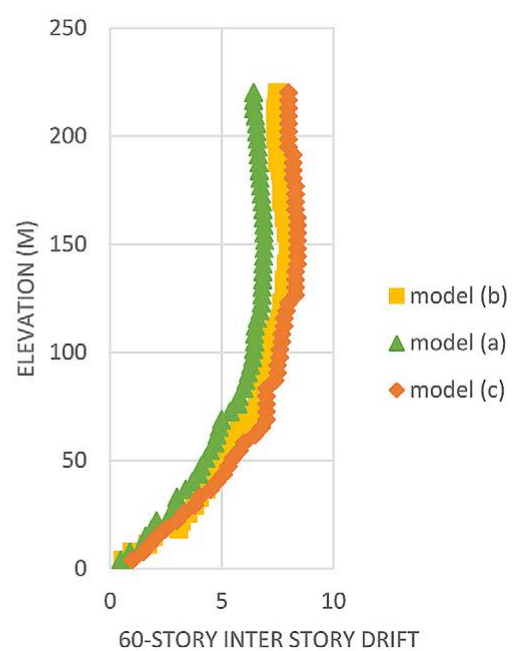

Fig. 4. Overall story drift and inter story drift for: a) 40-story building, b) 60-story building 
a)

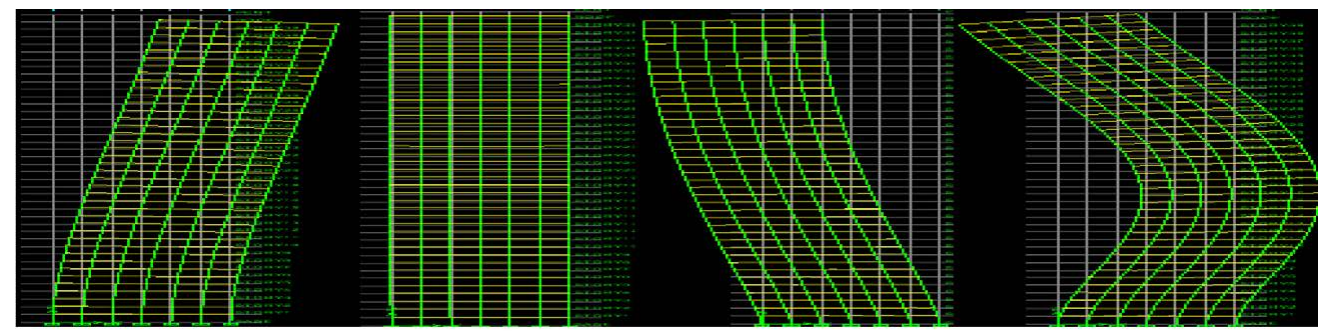

first mode second mode

third mode

fourth mode
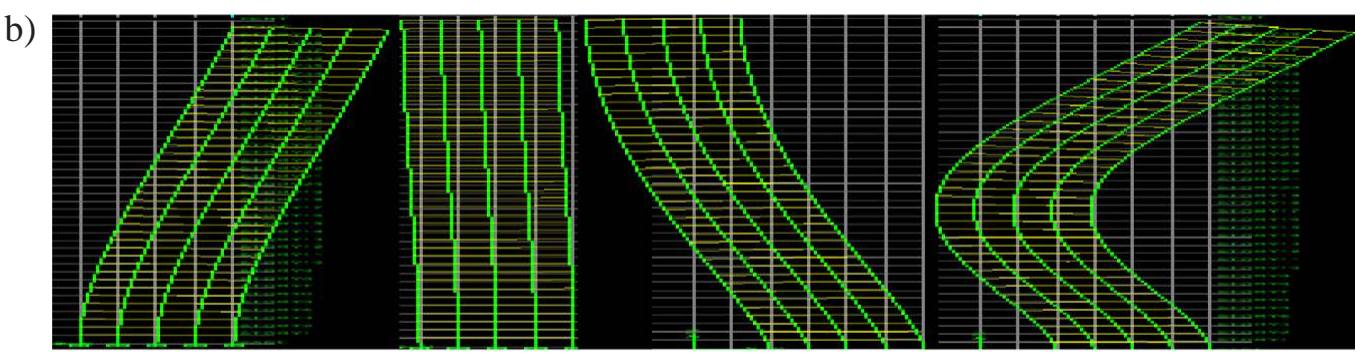

first mode

second mode

third mode

fourth mode

c)
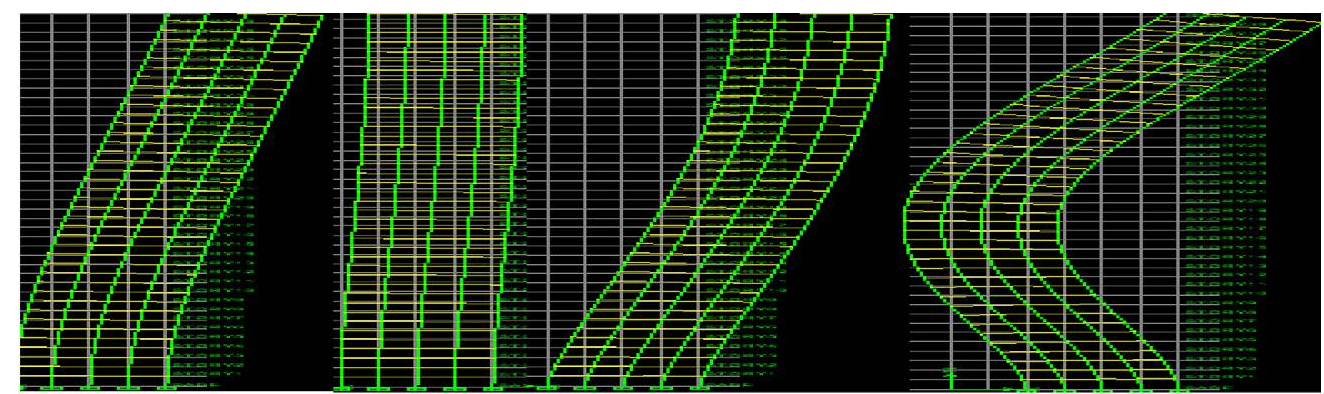

first mode

second mode

third mode

fourth mode

Fig. 5. First four modes of 40-story: a) model a, b) model b, c) model c

4 shows overall story drift and inter story drift 40 -story and 60-story building for plan model (a), (b) and (c) in X direction. As you can see in Figure 4 increase irregular of structure lade to increase overall story drift and inter story drift, also observed increase 60 -story building shoes significant growth story drift when irregular increase. Figure 5 shows the first four modes of the model (a), (b) and (c) for 40-story, as you can see irregular in plan of building changes shape of modes.

\section{COLUMN AXIAL FORCE AND SHEAR LAG PHENOMENA}

Column axial force is one of the importance parameters that performance of tube system evaluated with it. Figure 6 shows column axial force for south and west face of 40-srory and 60-story building. As one can see, in figures increase irregular in in plan of building amply shear lag phenomena, with increase irregular in plan shape of distribution column axial force getting away from liner state, with increase irregular in plan difference between columns axial force growth.

\section{CONCLUSIONS}

This paper evaluated seismic behavior of irregular building tube in tube systems, seismic performance of a 40-story and 60-story building tube system evaluated. Performance of the structures assessed by overall story drift, inter story drift and shear lag behavior, observed irregular in plan of structure increase overall building drift and inter story drift, in the 60-story building with increase irregular in plan story drifts growth more than the 40-story drift, max difference story drift between regular plan and irregular plan in 40-story building was about $13 \%$, while max difference story drift between regular plan and irregular plan in the 40 -story building was about $18 \%$. Also observed in regular plan, proportion irregular plan shape of the column axial force is nearest to the linear state and increase irregular in plan of structure increase difference of the column axial force. 
a)

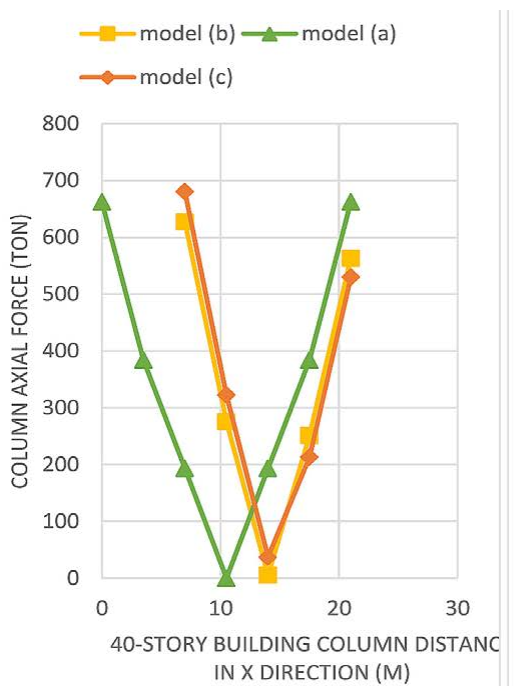

b)

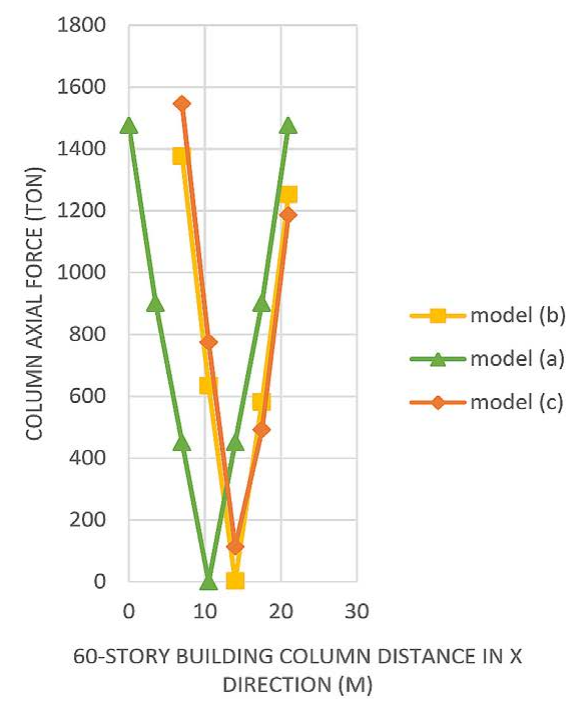

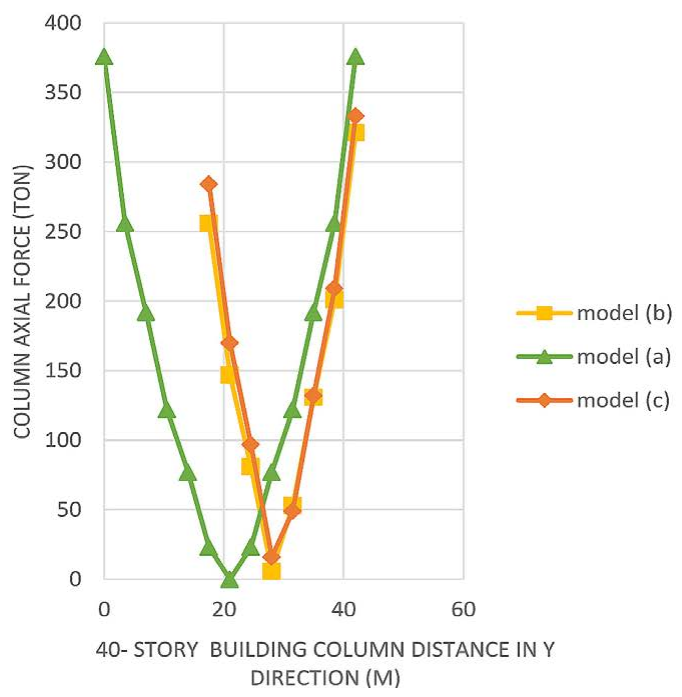

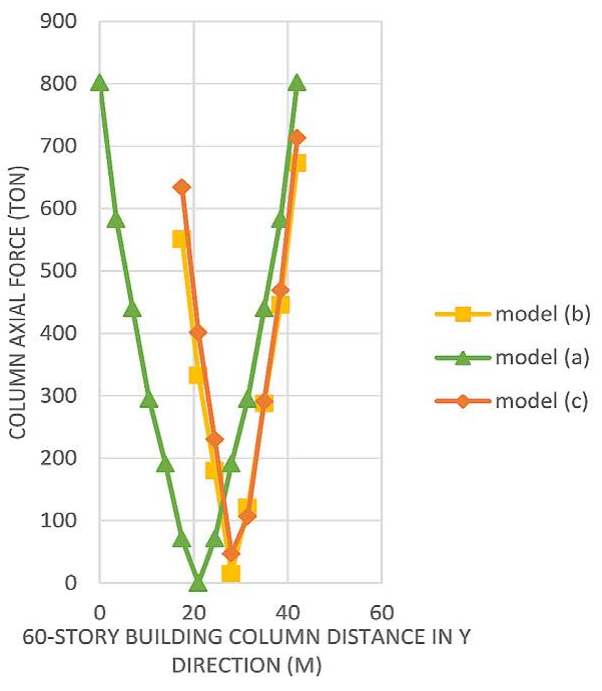

Fig. 6. Column axial force for south and west face of: a) 40-story building, b) 60-story building

\section{REFERENCES}

1. Murty C.V.R. Earthquake tips-IITK. Building Materials and Technology Promotion, NICEE, New Delhi 2009.

2. Athanatopoulou A.M., Makarios T. and Anastassiadis K. 2006. Earthquake analysis of isotropic asymmetric multistory buildings. The Structural Design of Tall and Special Buildings, 15(4), 417-443.

3. Roy R. and Chakroborty S. 2013. Seismic demand of plan-asymmetric structures: a Revisit. Earthquake Engineering and Engin. Vibration, 12(1), 99-117.

4. Kristek V, Bauer K. 1993. Stress distribution in front columns of high rise buildings. ASCE Journal of Structural Engineering, 115(5), 1326-1337.

5. Lee K-K, Lee L-H, Lee E-J. 2002. Prediction of shear-lag effects in framed-tube structures with internal tube(s). The Structural Design of Tall Buildings, 11, 73-92.

6. Singh Y, Nagpal K. 1994. Negative shear lag in framed-tube buildings. ASCE Journal of Structural Engineering, 120(11), 3105-3121.
7. CEN 2004. Eurocode 8: Design of structures for earthquake resistance - Part 1: General rules. Seismic Actions and Rules for Buildings, EN 1998-1, Brussels, Belgium.

8. Magliulo G., Maddaloni G. and Cosenza E. 2007. Comparison between non-linear dynamic analysis performed according to EC8 and elastic and nonlinear static analyses. Engineering Structures, 29(11), 2893-2900.

9. IS 1893 (Part 1) 2002. Indian standard criteria for earthquake resistant design of structures, Part 1 General provisions and buildings (Fifth Revision).

10. Computers and Structures Inc. 2011. CSI analysis reference manual. Computers and Structures Inc.

11. Berkeley C.A., Haji-Kazemi H., Company M. 2011. Exact method of analysis of shear lag in framed tube structures. The Structural Design of Tall Buildings, 11, 375-388.

12. ACI 318. 2008. Building code requirements for structural concrete (ACI 318-08) and commentary (318R-08). American Concrete Institute, Farmington Hills, MI. 